\title{
TYPES AND TASKS OF PEDAGOGICAL CONFLICTS
}

\author{
Ibrakhimov Sanjar Urunbayevich (Phd)
}

Uzbek Scientific Research Institute Of Pedagogical Sciences, Doctoral Student, Uzbekistan

\section{ABSTRACT}

This article presents information that shows primary causes of pedagogical inconsistencies as well as provides necessary data about types of pedagogical conflicts. Moreover, this paper discusses the views concerning this issue and how these conflicts may be solved within teacher-student interaction.

KEYWORDS:- Pedagogy, conflict, teacher, students, non-content, positive conflict, stabilizing conflicts, individual conflicts

\section{INTRODUCTION}

The educator's work on himself is represented by his practical actions as a specialist in the hunt for strategies to prevent and eradicate negative educational conflicts. As a student leader, the instructor must ensure that all of his or her creative activities at educational institutions are completed, as well as form a pedagogical orientation. Conflict is one of the most significant aspects of the educational process.

Dispute is defined as a clash of opposing, incompatible forces, a lack of mutual agreement between two or more parties, or a conflict with a conflict of interest [1].

Many specialists have focused their attention on pedagogical inconsistencies. In particular, Z Freud [2] demonstrated in his research that there are three psychological causes of group conflict:

1) the emergence of a common, undeniable negative attitude among members of one group toward members of another group in any intergroup cooperation;

2) the task of this negative attitude is to ensure the stability and consensus of the group members;

3) the mechanisms of hostility toward others and the manifestation of care, loyalty to one's own.

Conflict within groups, as L.G. Pochebut and V.A. Chiker point out, is an expression of interaction and cooperation in the activity process. As a result, such inconsistencies can be both beneficial and stabilizing [3].

Non-content disagreements might jeopardize the group's norms and ideals, preventing it from progressing to the next stage of growth.

It might also lead to the group returning to old norms and ideals. As a result, more individuals are drawn into the conflict, the number of 
CURRENT RESEARCH JOURNAL OF PEDAGOGICS 2(11): 143-146,

November 2021 DOI: https://doi.org/10.37547/pedagogics-crjp-02-11-27

ISSN 2767-3278

(C)2021 Master Journals

Crossref do) 81 Google

Accepted $25^{\text {th }}$ November, 2021 \& Published $30^{\text {th }}$ November, 2021

differences grows, and the disputing parties' relationship deepens at the expense of negative experiences. As a result, corruption and dishonesty become more widespread. As a result, the learning activities of group members become less effective. The possibilities of a peaceful resolution are slim due to the intricacy of the disputes. As a result, contentless contradictions are inherently damaging.

Positive conflicts refer to the diversity of viewpoints that influence a community's and its members' daily activities. Positive conflicts, as opposed to non-content conflicts, have the potential to keep group members stable amid shifting conditions. Its fundamental objective, as well as the composition of the group, is to repair the parties' connection. At the same time, the members of the group look for a clear, effective way to resolve the conflict that has arisen in collaboration with the educator. As a result, the team achieves a new, qualitatively higher level of performance. This is an important guiding force for learners 'personal development.

Stabilizing conflicts are the third type of conflict within groups, and they prevent deviations from norms, consolidate existing standards, and ensure equality among group members.

Individual conflicts are influenced not only by the specificity of situations and relationships, but also by the individual's personal traits. As a result, the community and its inhabitants are impacted in a variety of ways. A group leader is frequently involved in this process. According to L.G. Pochebut and V.A. Chiker, interpersonal conflicts can be caused by a variety of factors, including individual team member characteristics, a person's specific attitude toward a situation, and psychological aspects of interpersonal relationships.

Regardless of how interpersonal conflicts are generally classified, N.V. Grishina points out that they also apply to production conflicts.
Conflicts have both beneficial and negative consequences for the parties involved. The responsibilities of pedagogical conflict are critical for the educational process and for teachers to comprehend and uncover new attributes in their students. This implies that educational inconsistencies are multiparametric. Learners' progress is ensured by conflicts in particular settings, and they are able to ascend to a new qualitative level of activity as a result. There are also instances where conflicts within a group of learners cause divisions, resulting in disruption and the establishment of new groups. Educators working with such groups must be consistent in their approach to education. To accomplish so, they'll require a thorough examination of the group's goals and objectives. Educators understand that contradictions aren't always a bad thing.

a) to learn more about the conflict's parties and their differing points of view;

b) be able to assess it as a social pedagogical phenomena that allows for the identification of a wide range of different points of view and issues. This permits educators to ensure that the pedagogical method for resolving conflict situations is effective. It also allows a group of students with differing viewpoints to express themselves and address their own needs. As a result, educators must develop pedagogical conflicts and effective solutions not only to secure the efficacy and personal safety of the educational process, but also to explore learners.

Every conflict scenario should be conducive to the effective growth of the learners who are involved. It is highly dependent on the educator's ability to handle problems and keep a positive tone in the classroom.

The range of approaches regarding contradictions can be seen in the science of teaching, as well as other domains. While one group of scholars views contradictions in the 
CURRENT RESEARCH JOURNAL OF PEDAGOGICS 2(11): 143-146,

November 2021 DOI: https://doi.org/10.37547/pedagogics-crjp-02-11-27

ISSN 2767-3278

(C)2021 Master Journals

Crossref doi) 81 Google

Accepted $25^{\text {th }}$ November, 2021 \& Published $30^{\text {th }}$ November, 2021

educational process as a natural state, another group of scholars approaches it as a negative state.

They are attempting to discern between two sorts of instructional inconsistencies. The first is that if this conflict is related to the natural character of the interconnected pedagogical structures and offers the circumstances for their development, it is the basis for the development of the pedagogical process. The second type of conflict is random conflict, which occurs as a result of poor judgments made by teachers and school administrators. Such actions are viewed as inconsistencies that obstruct instructors' ability to work meaningfully and result in undesirable effects.

Conflict, according to M.M. Rybakova and A.G. Kovalev, is a disruptive phenomenon that disrupts the educational process. They suggest that disagreements within the realm of instructional activity have a negative impact on teacher-student relationships. Teachers feel dissatisfied with their employment and fearful as a result [4]. In turn, V.A Sukhomlinsky called the contradictions "a great tragedy of the educational institution."

It's worth noting that the shift in views toward instructional inconsistencies necessitates instructors taking a more objective approach to the problem. Today, S.A. Belkin, V.I. Juravlev, A.L. Krupenin, I.M. Krokhina, and N.V. Samsonova recognize the creative potential of pedagogical contradictions [5]. They consider the system of inter-learner conflicts to be severe and troublesome. This could be tied to a variety of learner development possibilities. Contradictions appear in the instructional process as both a unifying feature for learners and a means of splitting contending parties. The creation of a new system is based on conflicts between the two systems. This structure, in and of itself, embodies the integrity of a new identity.
To date, the number of works devoted to the study of educational paradoxes may be counted on one hand.

When it comes to recognizing instructional inconsistencies, experts primarily rely on theoretical approaches used in other fields. While one set of scholars focuses on the various degrees of contradictions that exist between educational participants, others consider the pedagogical system as a naturally occurring state of vital activity. Conflict resolution is a distinguishing aspect of existing methods to educational difficulties. A number of researchers have developed theoretical and practical techniques to justifying educational inconsistencies. On some issues connected to pedagogical paradoxes, researchers have different perspectives and discussions.

Pedagogical contradictions have been studied by V.I. Andreev, M.M. Rybakova, and T.A. Chistyakova, among others, who have based their conflicts on conflicting students. They remind out that clashing situations are built on open and closed conflicts. They are especially important to the objects of the conflict process since each of the warring parties has its own aims, preferences, desires, means, and approaches to address problems.

The concept of conflicting situations, according to T.A. Chistyakova, is a complex educational situation in which regretful situations are interconnected and can replace one another. A conflict can arise in any position taken by a teacher trying to resolve the contradiction through the chosen interaction strategy. Experienced, established teachers use a compromise / cooperation strategy when interacting with a student. But they are the most difficult to implement in practice. Therefore, teachers can use direct psychological suppression of the student to solve the problem, that is, the strategy of rivalry. It is expressed in 
CURRENT RESEARCH JOURNAL OF PEDAGOGICS 2(11): 143-146,

November 2021 DOI: https://doi.org/10.37547/pedagogics-crjp-02-11-27

ISSN 2767-3278

(C)2021 Master Journals

Crossref do: 81 Google

Accepted 25th November, 2021 \& Published 30 ${ }^{\text {th }}$ November, 2021

the position of affirming the unchanging correctness of the teacher and his selfconfidence. At the same time, students may feel inferior. Occasionally educators, in order to escape conflict or in an effort to adapt to students, adhere to an adjustment / avoidance strategy. Conflict avoidance is most often associated with the inability of adults to correctly formulate and present their requirements to the educated. In the face of an ethical choice, a contradictory educator, according to the author, must apply professional answers. Conflicts are a relationship-shattering event, and the struggle between educators and learners is driven by contradicting evidence. As a result, sports coaches, like all other educators, must be conversant with the various forms of conflicts that might arise between learners, their roles, and their personalities. This requires the inclusion of pedagogical contradictions in the process of training future sports coaches, their role in the species, ways to develop the pedagogical knowledge of coaches on how to overcome conflicts between athletes.

Summing up, the student-teacher interaction can be enhanced by a number of strategies and education on types of conflicts that may occur in the classroom or in general working with the students. Based on the information mentioned above, there are three dominant reasons for problem during the class to appear, including negative attitude being prevalent and one's idea that there is the manifestation of care. In addition, we can point out a number of types of conflicts that usually happen in pedagogical process. It is considered to be important to identify each of them by unique characteristics in order to make teaching process as much effective as possible. Even though the conflict is believed to be the disruptive phenomenon in the pedagogy, it still has to happen at one stage of teaching-learning process, since students' views and opinions may change very fast and they may face some difficulties with the content delivery and teacher's attitude that bring the whole class together or tears it apart. However, it is vital to mention that in some cases group conflicts lead to beneficial results that develop student's competitor skills and motivates them to do even better than they already do. Thus, a number of contradictions on this pedagogical issue make it difficult to draw one standard conclusion from teacher-learner conflicts.

\section{ReFERENCES}

1. Ahmedova M. Textbook "Pedagogical conflictology" // Tashkent. 2015.

2. Freud Sigmund. Basic psychological theories in psychoanalysis // Moscow, 2006. - 400 p.

3. Study of L. G., Chiker V.A. Organizational social psychology. Tutorial. SPb .: Publishing house "Rech", 2002. - 298 p.

4. Rybakova M.M. - Conflict and interaction in the pedagogical process // Moscow: Education, 1991. - 128 p.

5. Zhuravlev I.V. The problem of consciousness in the activity paradigm // Theoretical and practical aspects of psychology and pedagogy: Collective monograph. - Ufa: Aeterna, 2015.S. 107-134. 